\title{
Multiple Sexual Partners and Vulnerability to HIV: A Study of Patterns of Sexual Behaviour in the Slum Population of India
}

\author{
Pravin K. Jha1, Damodar Sahu'², K. Srikanth Reddy², Padum Narayan², Arvind Pandey² \\ ${ }^{1}$ Centre for Study of Regional Development, Jawaharlal Nehru University, New Delhi, India \\ ${ }^{2}$ National Institute of Medical Statistics, New Delhi, India \\ Email: sahud@icmr.org.in
}

Received 30 August 2014; revised 25 September 2014; accepted 21 October 2014

Copyright (C) 2014 by authors and Scientific Research Publishing Inc.

This work is licensed under the Creative Commons Attribution International License (CC BY). http://creativecommons.org/licenses/by/4.0/

(c) (i) Open Access

\begin{abstract}
Globally, research indicates that monogamous married women living in slums are at heightened risk of HIV men's risky sexual behaviour. Hence, to reduce the risk of HIV transmission, there is need to understand the number, nature and variation in transition of sexual partners of men in living in slums. This paper uses India's National Family Health Survey-3 data to estimate the variation in the type of sexual partners among sexually active men age 15 - 54 with more than one sexual partner in last 12 months prior to the survey in eight slums of India. Among sexually active men, 1.3 percent reported having more than one sexual partner in the last 12 months prior to the survey. Men who are more likely to have two or more partners are those who are young, especially below age 25 years, never married, educated up to 5 years, and from middle class. There is a higher increase in the probability of sex with spouse from second last to the last sexual partner in non-slum areas than slum areas. However, in case of transition from other friends/relatives and female sex workers to spousal partners, there is a major decline in probability among non-slum men than slum men. These transitions are extremely important from the perspective of curbing the spread of HIV epidemic, especially in situations where women lack control over their own sexuality and seldom use condom in marital sex. Therefore, strategies focused in slums should either consider reducing men's risky sexual behaviour or build capacities of women to negotiate safe sex in marital relationships or consider a combination of both.
\end{abstract}

\section{Keywords}

Slum, Sexual Partners, Transition Probability

\footnotetext{
*Corresponding author.
}

How to cite this paper: Jha, P.K., Sahu, D., Reddy, K.S., Narayan, P. and Pandey, A. (2014) Multiple Sexual Partners and Vulnerability to HIV: A Study of Patterns of Sexual Behaviour in the Slum Population of India. World Journal of AIDS, 4, 373-381. http://dx.doi.org/10.4236/wja.2014.44044 


\section{Introduction}

The HIV prevalence rate in India is estimated at $0.27 \%(0.22 \%-0.33 \%)$ in 2011 and is steadily declining. Despite $57 \%$ reduction in new infections, due to a large population, India is estimated to have around 116,000 annual new HIV infections among adults [1] and is concentrated in the age group of 25 - 34 [2]. India's HIV epidemic is heterogeneous and concentrated in nature with high prevalence among high risk groups [3]. However, growing body of research the heightened vulnerability of women in monogamous relationship due to their husband's/partner's risky sexual behaviour [4]. This vulnerability is further aggravated among women living in slum communities as there is ample evidence to suggest that infection rates are higher in urban areas and slum dwellers tend to be disproportionately affected [5] [6].

Men living in slums are more likely to indulge in risky behaviour and have multiple sexual partners than those living in formal housing with better social and living environment [7]. These behaviours are mainly an outcome of peer pressure, social network, easy availability of country liquor, presence of local breweries and video parlours, lack of healthy means of entertainment, lack of proper and complete knowledge about sexuality and HIV/ AIDS. Additionally, migrants in slums are more prone to indulge in risky behaviour due to availability of some disposable income coupled with social and environmental factors.

Multiple sexual partnerships are a core indicator used in assessing an individual's risk level. This coupled with non use of consistent use of condom increases the risk of HIV. Almost one-thirds of HIV positive men reported to have two or more sexual partners in their life time [2]. Therefore, it is important to understand different dimensions of risky sexual behaviours including number and types of sexual partners and their indulgence in unprotected sexual activities among adult men. The paper views that the numbers and nature and pattern in partner exchange rate and adaptation of safe sexual practices play a pivotal role in the transmission of HIV epidemic from high risk to low risk population. Hence, it is important to understand the variation in transition of the sexual partners.

The paper has tried to assess by using NFHS-3 data about the pattern of sexual partnerships, variation in sexual partner's transition among slum and non-slum populations, prevalence of HIV infection across the social strata, and the types and frequency of sexual practices. Nevertheless paper this may facilitate in analyzing the consistent use of condom among partners through negotiations for prevention of HIV infection and STD transmission among slum and non-slum population.

\section{Material and Methods}

In this paper, we used India's National Family Health Survey-3 (NFHS-3) data to estimate the variation in the type of sexual partners among sexually active men aged 15 - 54 with more than one sexual partner in last 12 months prior to the survey [2] [8] [9]. The NFHS-3 was carried out in 2005-06 by the Ministry of Health and Family Welfare, Government of India, in association with the International Institute for Population Sciences, Mumbai, serving as the nodal agency. NHFS-3 provided separate estimates of population, health, and nutrition indicators for eight cities (Chennai, Delhi, Hyderabad, Indore, Kolkata, Meerut, Mumbai, and Nagpur) and for the slum and non-slum populations in each of these cities. The survey was done with a representative sample of approximately 2000 households with about 1000 households each from enumeration areas designated as slum and non-slum areas within the municipal corporation limits of these cities according to the 2001 census. State weights were used to correct for the oversampling, so that indicators based on these data are representative at the city level, as well as for slum and non-slum areas within the cities [8]-[10]. The paper specifically used data on sexually active men aged 15 - 54 with more than one sexual partner including the last partner and the second last sexual partner in last 12 months prior to survey.

\subsection{Measures}

In the NHFS-3 survey, respondent were asked how many sexual partners they had in the past 12 months. The reason for 12 month reporting period was to minimize recall errors, and include a large portion of a respondent's sexual life to be statistically meaningful. Respondents who reported two or more sexual partners in the last 12 months were categorized as having multiple sexual partners.

Standard socio-demographic and behavioural measures were obtained that assessed respondents age ( $\leq 24$, 25 - 34, 35 - 44, 45 and above), education (in years), marital status (never married-including gauna not per- 
formed, married living with wife, married living elsewhere, widow/divorced/separated/deserted), pre-marital sex, consistent condom use, wealth index (poorest, poorer, middle, richer, richest) and place of residence (slum, nonslum). In this analysis, "never married" and "gauna not performed” were grouped together, as these categories are usually similar in terms of risk factors. The types of sexual partners have been categorized into five groups namely Spouse; Girlfriend/Live-in-partners; Other friends/relatives; Casual acquaintances/others and Female sex workers in order to have meaningful insights in to the risk behaviour [2] [9].

\subsection{Statistical Model}

We used the discrete markov chain model [2] to estimate the transition probabilities of sexual partners among sexually active men aged 15 - 54 with more than one sexual partner in the year preceding survey.

Description of a Markov Chain is as follows:

Let $S=\left\{s_{1}, s_{2}, \cdots, s_{k}\right\}, k=5$, is the state space of stochastic process. The process starts in one of these states and moves successively from one state to another. Each move is called a step. If the chain is currently in the state $s_{i}$, then it moves to state $s_{j}$ at the next step with a probability denoted by $p_{i j}$, and this probability does not depend upon which states the chain was in before the current state. The probabilities $p_{i j}$ are called transition probabilities that the respondents having earlier sexual relation with sexual partner $i$ moves to partner $j$ during the sexual encounter with last type of partner, where sexual encounters with both the sexual partners have occurred in the 12 months prior to the survey $(i, j=1,2, \cdots, k ; k=5)$. The process can remain in the state it is in, and this occurs with probability $p_{i i}$.

These transition probabilities satisfied the following properties:

$$
p_{i j} \geq 0 \text { and } \sum_{i=1}^{k} p_{i j}=1 .
$$

and the matrix $P=\left(p_{i j}\right)$ is the transition matrix of the chain.

Suppose that $p_{10}, p_{20}, p_{30}, \cdots, p_{k o}$ are the probabilities that respondent has sexual relations with $S_{1}, S_{2}, \cdots, S_{k}$ type of partners in their sexual intercourse with the second last sexual partner and under the condition that the probability of moving from $i^{\text {th }}$ type of sexual partner to the $j^{\text {th }}$ type of sexual partner does not depend upon how it reaches to the $j^{\text {th }}$ place, one step current probabilities $p_{1 c}, p_{2 c}, \cdots, p_{k c}$ of a respondent to have sexual intercourse with different type of sexual partners $S_{1}, S_{2}, \cdots, S_{k}$ can be obtained using the formula, if the probability of $p_{i o}$ and $p_{i j}$ are known:

$$
p_{j c}=\sum_{i=1}^{k} p_{i o} p_{i j} \text { for } j=1,2,3, \cdots, k
$$

where $p_{i o}=n_{i o} / n$ and $p_{i j}=n_{i j} / n_{i o}$.

$n_{i o}=\sum_{i=1}^{k} n_{i j}$ and $n_{i j}$ that is the number of respondents having relationship to their second last sexual partners $S_{i}$ and moved to have sexual intercourse with type of partners $S_{j}$ currently for one step for $i \& j=1,2,3 \cdots$, $k$. The $p_{j c}$ is given by [4]:

$$
p_{j c}=\sum_{i=1}^{k} p_{i o} p_{i j} \text { for } j=1,2,3, \cdots, k
$$

\section{Results}

In the present study about 61\% men had ever experienced sexual intercourse while it was observed that of these about $91 \%$ were sexually active in the last 12 months. Among sexually active men, 1.3 percent reported having more than one sexual partner in the last 12 months prior to the survey. Table 1 shows the distribution of sexually active men in the year preceding survey by the selected characteristics. Fewer men are under 25 years of age; percent of slum population in this age group two times higher than in non-slum areas. Nearly half the men have had more than 10 years of education; in comparison to slum, more non-slum men have had more than 10 years of education. Overall, about $86 \%$ of married men are living with their wife whereas in non-slum about $90 \%$ and in slum about $80 \%$ are living with their wife. In slum $9.4 \%$ men have had pre-marital sexual relation in comparison to $6 \%$ of men living in non-slum. About $88 \%$ of men reported of using condom consistently and there is slight difference in condom use among slum and non-slum men. More than half of the men interviewed are richest in the study population. The proportion of richest men is higher in non-slum areas; however, the proportion of richer men is higher in slum areas.

Table 2 presents percentage distribution of men aged 15 - 54 by number of sexual partners in the year preceding 
Table 1. Number and percentage distribution of men aged 15 - 54, by selected background characteristics according place of residence, eight cities sample, NFHS-3, 2005-2006.

\begin{tabular}{lccccccc}
\hline & \multicolumn{2}{c}{ Slum Area } & \multicolumn{2}{c}{ Non-Slum Area } & \multicolumn{3}{c}{ Combined } \\
\cline { 2 - 8 } & Background characteristic & N & $\%$ & N & $\%$ & N & $\%$ \\
\hline Total & 896 & 100 & 1603 & 100 & 2498 & 100
\end{tabular}

Age (Years)

$\leq 24$
$25-34$
$35-44$
$\geq 45$

$\begin{array}{rrrrrr}113 & 12.6 & 102 & 6.4 & 215 & 8.6 \\ 331 & 37.0 & 542 & 33.8 & 873 & 35.0 \\ 287 & 32.0 & 587 & 36.6 & 874 & 35.0 \\ 165 & 18.4 & 372 & 23.2 & 536 & 21.5\end{array}$

\section{Education (Years)}

No Education
$<5$
$5-9$
$\geq 10$

$\begin{array}{cccccc}98 & 10.9 & 125 & 7.8 & 222 & 8.9 \\ 71 & 7.9 & 79 & 4.9 & 150 & 6.0 \\ 399 & 44.5 & 442 & 27.6 & 840 & 33.6 \\ 328 & 36.7 & 958 & 59.8 & 1286 & 51.5\end{array}$

\section{Marital Status}

Never Married

Married Living with Wife

Married Living Elsewhere

Widow/Divorced/Separated/Deserted

\section{Pre-Marital Sex}

Yes

\section{Consistent Condom Use}

Yes

\section{Cities}

Delhi City

Meerut

Kolkata

Indore

Mumbai

Nagpur

Hyderabad

Chennai

Wealth Index

Poorest
Poorer
Middle
Richer
Richest

$\begin{array}{cccccc}59 & 6.6 & 75 & 4.7 & 134 & 5.4 \\ 715 & 79.9 & 1437 & 89.7 & 2152 & 86.2 \\ 117 & 13.1 & 87 & 5.5 & 204 & 8.2 \\ 5 & 0.5 & 3 & 0.2 & 7 & 0.3\end{array}$

84

783

170

29

34

10

507

45

42

60

4

22

134

367

370
9.4

87.4

1421

19.0

3.2

3.8

1.1

56.6

5.0

4.6

6.7

0.4

2.5

14.9

40.9

41.3

1111

590

36

41

343

84

247
6.1

182

7.3

88.7

2204

88.2

36.8

760

30.4

2.2

64

2.6

4.0

98

3.9

2.5

2.0

21.4

51

34.0

5.2

849

5.2

12.4

129

5.2

15.4

240

9.6

12.3

307

0.3

1.9

9.1

29.4

59.3 
Table 2. Percentage distribution of men aged 15 - 54 by number of sexual partners in the year preceding the survey, according to selected background characteristics, eight cities sample, NFHS-3, 2005-2006.

\begin{tabular}{|c|c|c|c|c|c|c|c|c|c|}
\hline \multirow{2}{*}{ Characteristic } & \multicolumn{3}{|c|}{ Slum Area } & \multicolumn{3}{|c|}{ Non-Slum Area } & \multicolumn{3}{|c|}{ Combined } \\
\hline & $\mathrm{N}$ & 1 & $1<$ & $\mathrm{N}$ & 1 & $1<$ & $\mathrm{N}$ & 1 & $1<$ \\
\hline & & $\%$ & $\%$ & & $\%$ & $\%$ & & $\%$ & $\%$ \\
\hline Total & 896 & 98.1 & 1.8 & 1603 & 99.0 & 1.0 & 2498 & 98.7 & 1.3 \\
\hline \multicolumn{10}{|l|}{ Age (Years) } \\
\hline$\leq 24$ & 113 & 95.1 & 4.9 & 102 & 92.8 & 7.2 & 215 & 94.0 & 6.0 \\
\hline $25-34$ & 331 & 97.9 & 2.1 & 542 & 99.4 & 0.6 & 873 & 98.8 & 1.2 \\
\hline $35-44$ & 287 & 99.0 & 1.0 & 587 & 99.5 & 0.5 & 874 & 99.3 & 0.7 \\
\hline$\geq 45$ & 165 & 99.1 & 0.9 & 372 & 99.4 & 0.6 & 536 & 99.3 & 0.7 \\
\hline
\end{tabular}

\section{Education (Years)}

No Education
$<5$
$5-9$
$\geq 10$

Marital Status

Never Married

Married Living with Wife

Married Living Elsewhere

Widow/Divorced/Separated/Deserted

Pre-Marital Sex

Yes

Consistent Condom Use

Yes

\section{Cities}

Delhi City

Meerut

Kolkata

Indore

Mumbai

Nagpur

Hyderabad

Chennai

Wealth Index

Poorest

Poorer

Middle

Richer

Richest

$\begin{array}{ccccccccc}98 & 98.0 & 2.0 & 125 & 99.8 & 0.2 & 222 & 99.0 & 1.0 \\ 71 & 97.1 & 2.9 & 79 & 97.9 & 2.1 & 150 & 97.6 & 2.4 \\ 399 & 97.9 & 2.1 & 442 & 99.0 & 1.0 & 840 & 98.5 & 1.5 \\ 328 & 98.6 & 1.4 & 958 & 99.0 & 1.0 & 1286 & 98.9 & 1.1\end{array}$

$\begin{array}{ccccccccc}59 & 86.8 & 13.2 & 75 & 89.4 & 10.6 & 134 & 88.3 & 11.7 \\ 715 & 98.7 & 1.3 & 1437 & 99.5 & 0.5 & 2152 & 99.2 & 0.8 \\ 117 & 100.0 & 0.0 & 87 & 99.5 & 0.5 & 204 & 99.8 & 0.2 \\ 5 & 99.2 & 0.8 & 3 & 100.0 & 0.0 & 7 & 99.5 & 0.5\end{array}$

84

78

$\begin{array}{ccccccccc}170 & 96.6 & 3.4 & 590 & 99.3 & 0.7 & 760 & 98.7 & 1.3 \\ 29 & 96.6 & 3.4 & 36 & 97.5 & 2.5 & 64 & 97.1 & 2.9 \\ 34 & 98.6 & 1.4 & 65 & 98.9 & 1.1 & 98 & 98.8 & 1.2 \\ 10 & 98.8 & 1.2 & 41 & 98.0 & 2.0 & 51 & 98.2 & 1.8 \\ 507 & 98.9 & 1.1 & 343 & 99.3 & 0.7 & 849 & 99.0 & 1.0 \\ 45 & 96.8 & 3.2 & 84 & 98.9 & 1.1 & 129 & 98.1 & 1.9 \\ 42 & 97.6 & 2.4 & 198 & 98.6 & 1.4 & 240 & 98.4 & 1.6 \\ 60 & 97.7 & 2.3 & 247 & 98.8 & 1.2 & 307 & 98.5 & 1.5\end{array}$

\begin{tabular}{ccccccccc}
4 & 100.0 & 0.0 & 3 & 100.0 & 0.0 & 7 & 100.0 & 0.0 \\
22 & 98.1 & 1.9 & 25 & 100.0 & 0.0 & 48 & 99.1 & 0.9 \\
134 & 97.1 & 2.9 & 95 & 98.8 & 1.2 & 229 & 97.8 & 2.2 \\
367 & 98.0 & 2.0 & 368 & 99.1 & 0.9 & 735 & 98.6 & 1.4 \\
370 & 98.6 & 1.4 & 1111 & 99.0 & 1.0 & 1481 & 98.9 & 1.1 \\
\hline
\end{tabular}


the survey, according to background characteristics. Most men (98.7\%) had only one sexual partner during the year preceding the survey; $1.3 \%$ had more than one sexual partner. Nearly $1.8 \%$ men in Slum and $1.0 \%$ men in Non-slum reported having more than one sexual partner. The proportion of men with multiple sexual partners is higher among men who are under age 25 years than are 25 years or older; among under age 25 years it is higher in non-slum (7.2\%) than slum (4.9\%). Considerably a higher proportion of men with 5 years of education reported having multiple sexual partners. Nearly $11.7 \%$ never married men had multiple sexual partners during the year preceding the survey (13.2\% in slum, 10.6\% in non-slum). Among those who had pre-marital sexual relationship, 4.1\% men reported having more than one sexual partner; it is high among men in non-slum (5.9\%) than slum (2.1\%). Only $1.4 \%$ consistent condom users reported more than one sexual partner $(2.0 \%$ in slum; $1.0 \%$ in non-slum). Among Cities, overall higher proportion of multiple sexual partners was observed in Meerut followed by Nagpur, Indore, Hyderabad, Chennai, Delhi City, and Mumbai. Distribution by slum and non slum illustrates that it was higher among men in Delhi city and Meerut slum followed by Nagpur and Hyderabad whereas in non-slum, it was higher in Meerut followed by Indore and Nagpur. Almost 2.2\% men in middle class reported more than one sexual partner followed by richer, and richest. More slum men reported having multiple sexual partners than non-slum in all categories. Among slum, men in middle class reported having more multiple sexual partners followed by richer, and richest class. There was a modest decline with age in the proportion of men who reported multiple sexual partners among men in slum.

Table 3 presents percent distribution of men aged 15 - 54 years who had had multiple sexual partners in the year preceding the survey by their relationship with the last sexual partners and the second last sexual partners. It was reported that for $94.3 \%$ men the last partner was their spouses followed by girlfriends/live-in partners (3.7\%), friends or relatives (1.0\%), female sex workers $(0.7 \%)$, and casual partners $(0.2 \%)$. Fewer men $(0.9 \%)$ were engaged in sexual activity with previously unknown person. About $6.7 \%$ men in slum and $4.9 \%$ men in non-slum reported that their last partner was not their wives; they indulged in high risk sexual behaviour. Nearly 4.9\% men in slum had girlfriends/live-in-partners as the last sexual partners compared to 3.1\% men in non-slum. Slightly less men in slum reported having other friends and relatives as the last sexual partner than men in non-slum. Data in table reveals that a higher proportion of men in slum reported having female sex workers as the last sexual partner; $0.8 \%$ men in slum and $0.6 \%$ men in non-slum had female sex workers as the last sexual partner.

It is observed from Table 3 that spouses were not the main second last sexual partner. For men in slum and non-slum areas the main second last sexual partner were their girlfriends/fiancé, other friends/relatives, casual acquaintance and female sex workers; Only 15.2\% men reported that their second last partner were their wives; nearly 6 percent of men mentioned casual acquaintances, 27 percent female sex workers, 36.4 percent girlfriends/fiancé/live-in partners and $12 \%$ of men mentioned other friends or relatives other than their wives. Most

Table 3. Percentage distribution of men age 15 - 54, by their relationship with the sexual partners in the year preceding the survey, eight cities sample, NFHS-3, 2005-2006.

\begin{tabular}{|c|c|c|c|c|c|c|}
\hline $\begin{array}{l}\text { Background } \\
\text { characteristic }\end{array}$ & Spouse & $\begin{array}{l}\text { Girlfriend/Fiancé/ } \\
\text { Live-in-partners }\end{array}$ & $\begin{array}{l}\text { Others friends/ } \\
\text { Relatives }\end{array}$ & $\begin{array}{c}\text { Casual acquaintance/ } \\
\text { Others }\end{array}$ & $\begin{array}{l}\text { Female sex } \\
\text { workers }\end{array}$ & Total \\
\hline \multicolumn{7}{|c|}{ Types of the last sexual partners } \\
\hline \multicolumn{7}{|l|}{ Place of residence } \\
\hline Combined & 94.30 & 3.70 & 1.00 & 0.20 & 0.70 & 2498 \\
\hline Slum area & 93.30 & 4.90 & 0.90 & 0.20 & 0.80 & 896 \\
\hline Non-slum area & 95.10 & 3.10 & 1.00 & 0.20 & 0.60 & 1602 \\
\hline \multicolumn{7}{|c|}{ Types of the second last sexual partners } \\
\hline \multicolumn{7}{|l|}{ Place of residence } \\
\hline Combined & 15.20 & 36.40 & 12.10 & 6.10 & 27.30 & 33 \\
\hline Slum area & 25.50 & 39.40 & 11.70 & 6.70 & 16.70 & 17 \\
\hline Non-slum area & 4.70 & 36.20 & 15.50 & 5.90 & 37.80 & 16 \\
\hline
\end{tabular}


men have reported female sex workers and girlfriends/fiancé/live-in-partner as their second last sexual partner. Only one fourth men in slum areas reported having their wives as the second last partner compared to $39.4 \%$ who reported girlfriends/fiancé/live-in-partner, $11.7 \%$ who reported other friends/relatives, $6.7 \%$ who reported casual acquaintance and $16.7 \%$ who reported female sex workers as the main second last sexual partner. Among men in non-slum areas a very large proportion of men reported not having their wives as the main second last partner. Only, $4.7 \%$ men reported having their wives as the main second last partner; while $36.2 \%$ reported girlfriends/fiancé/live-in-partner, $15.5 \%$ reported other friends/relatives, 5.9\% reported casual acquaintance and $37.8 \%$ reported female sex workers as the main second last partner.

Table 4 presents the estimates of transition probabilities for the types of second last sexual partners to the types of last sexual partners among men having multiple sexual partners in the year preceding survey. For men whose second last partners were their wives, the transition probability to have their wives as their last partner was 0.81 . The transition probabilities of such respondents from spouse to girlfriend/fiancé/live-in partner or other friends or relatives or female sex workers, as the last sexual partners, were $0.03,0.12$ and 0.04 respectively. While, the transition probabilities from girlfriend/fiancé/live-in partner or other friends or relatives or casual

Table 4. Estimates of the transition probabilities for the type of second last sexual partner to the Type of last sexual partner by the place of residence, eight cities sample, NFHS-3, 2005-2006.

\begin{tabular}{|c|c|c|c|c|c|}
\hline & \multicolumn{5}{|c|}{ Types of last sexual partners } \\
\hline & Spouse & $\begin{array}{l}\text { Girlfriend/Fiancé/ } \\
\text { Live-in-partners }\end{array}$ & $\begin{array}{l}\text { Others friends/ } \\
\text { Relatives }\end{array}$ & $\begin{array}{c}\text { Casual acquaintance/ } \\
\text { Others }\end{array}$ & $\begin{array}{l}\text { Female sex } \\
\text { workers }\end{array}$ \\
\hline Spouse & 0.81 & 0.03 & 0.12 & 0.0 & 0.04 \\
\hline Girlfriend/Fiancé/Live-in-partners & 0.40 & 0.55 & 0.03 & 0.0 & 0.02 \\
\hline Others friends/Relatives & 0.73 & 0.17 & 0.07 & 0.0 & 0.03 \\
\hline Casual acquaintance/Others & 0.46 & 0.04 & 0.00 & 0.0 & 0.5 \\
\hline Female sex workers & 0.27 & 0.17 & 0.01 & 0.0 & 0.55 \\
\hline$p_{i .}$ & 0.15 & 0.37 & 0.13 & 0.06 & 0.26 \\
\hline$P_{j c}$ & 0.47 & 0.28 & 0.04 & - & 0.19 \\
\hline \multicolumn{6}{|c|}{ Slum } \\
\hline Spouse & 0.86 & 0.01 & 0.14 & 0.0 & 0.0 \\
\hline Girlfriend/Fiancé/Live-in-partners & 0.34 & 0.6 & 0.03 & 0.0 & 0.03 \\
\hline Others friends/Relatives & 0.7 & 0.2 & 0.09 & 0.0 & 0.02 \\
\hline Casual acquaintance/Others & 0.26 & 0.03 & 0.00 & 0.0 & 0.71 \\
\hline Female sex workers & 0.29 & 0.02 & 0.03 & 0.0 & 0.67 \\
\hline$p_{i .}$ & 0.25 & 0.39 & 0.12 & 0.07 & 0.17 \\
\hline$P_{j c}$ & 0.5 & 0.27 & 0.06 & - & 0.17 \\
\hline \multicolumn{6}{|c|}{ Non-slum } \\
\hline Spouse & 0.53 & 0.18 & 0.0 & 0.0 & 0.29 \\
\hline Girlfriend/Fiancé/Live-in-partners & 0.47 & 0.5 & 0.02 & 0.0 & 0.01 \\
\hline Others friends/Relatives & 0.76 & 0.15 & 0.05 & 0.0 & 0.04 \\
\hline Casual acquaintance/Others & 0.72 & 0.05 & 0.0 & 0.0 & 0.23 \\
\hline Female sex workers & 0.27 & 0.24 & 0.0 & 0.0 & 0.49 \\
\hline$p_{i .}$ & 0.05 & 0.35 & 0.15 & 0.06 & 0.37 \\
\hline$P_{j c}$ & 0.45 & 0.3 & 0.02 & - & 0.22 \\
\hline
\end{tabular}


acquaintance/others or female sex workers, as the second last partners to spouse as the last sexual partner, were $0.40,0.73,0.46$ and 0.27 respectively. The transition probabilities of those men having girlfriend/fiancé/live-in partner or female sex workers as the second last partners to the same category as their last sexual partners, were 0.55 and 0.55 respectively. The marginal probability $\left(p_{i}\right.$ and $p_{j c}$ ) shows that the probability of spouse being the sexual partner has increased from 0.15 in the second last sexual partner to 0.47 in case of the last sexual partner. In case of other four categories of non-spousal sexual relations there is a considerable decline in probabilities.

It was observed that the transition probability for men whose second last partners were their wives, to have their wives as their last sexual partners varied across slum areas and non-slum areas. The probabilities for transition from wives as second last partners, to wives as last sexual partners were observed higher among slum men than non-slum men $(0.86,0.53$ respectively). It was found that the transition from spousal to non-spousal or non-spousal to spousal partners, as the second last sexual partners to the last sexual partners, was slightly different among slum and non-slum men. In case of slum, it is observed that the probability of transition for spouse to other friends/relatives as the last sexual partners was 0.14 ; however, the probability of transition was reported as 0.27 for female sex workers as the last sexual partners in case of non-slum. The transition probabilities among slum men from casual partners to casual partners or female sex workers to female sex workers, as the second last to last sexual partners, were higher ( 0.71 and 0.67 respectively) than non-slum men $(0.23$ and 0.49$)$. There is a higher increase in the probability of sex with spouse from second last to the last sexual partner in non-slum areas than slum areas. However, in case of transition from other friends/relatives and female sex workers to spousal partners, there is a major decline in probability among non-slum men than slum men.

\section{Discussion}

According to National Family Health Survey (NFHS-3) in India, nearly 30 percent of adult men in India have never had sexual intercourse [2] [9]; however, our study shows that about 39\% of adult men in eight cities have never had sexual intercourse. Among those who ever experienced sexual intercourse, almost two-fifths of them have had two or more sexual partners [2] [9]; while it is $1.3 \%$ in selected eight slum cities. Men who are more likely to have two or more partners are those who are young, especially below age 25 years, never married, educated up to 5 years, and from middle class. Men with pre-marital sexual relationship and from Meerut and Nagpur cities are more likely to have multiple sexual partners. There is profound variation in the proportion of men indulging in high-risk sexual intercourse by their place of residence. The proportion of men with multiple sexual partners is higher among those living in slum than non-slum areas. However, the proportion of men under age 25 years with two or more sexual partners is higher in non-slum than slum population. Such risky sexual behaviours of men have serious implications due to the fact that the issue of protection or use of condom in these activities is compromised.

The finding shows that for most men, spouses are the main last sexual partner. However, interestingly, the second last partner is not confined only to spouse; it shows much more about partner preferences. Only 15\% - 20\% reported that their second last sexual partner was their spouse. For men in slum and non-slum areas the main second last sexual partner were their girlfriends/fiancé, other friends/relatives, casual acquaintance and female sex workers. It is a notable fact that higher proportion of men among slum population were reportedly having their spouses as the second last sexual partners in comparison non-slum. However, a higher proportion of non-slum's men were having female sex workers as their second last sexual partners than slum.

It was found that the transition from spousal to non-spousal or non-spousal to spousal partners, as the second last sexual partners to the last sexual partners, was slightly different among slum and non-slum men. The probabilities for transition from wives as second last partners, to wives as last sexual partners were observed higher among slum men than non-slum men (0.86, 0.53 respectively). It is observed that the probability of transition for casual acquaintance/other friends to spouse as the last sexual partners was 0.29 in slum areas as against 0.72 in non-slum areas. A relatively profound transition probability from non-spousal to non-spousal sexual relations in case of the second last sexual partner across slum-non slum place of residence is observed in case of female sex workers (0.67 in slum areas as against 0.49 in non-slum areas).

There is a higher increase in the probability of sex with spouse from second last to the last sexual partner in non-slum areas than slum areas. However, in case of transition from other friends/relatives and female sex workers to spousal partners, there is a major decline in probability among non-slum men than slum men. These transitions are extremely important from the perspective of curbing the spread of HIV epidemic, especially in 
situation where women lack control over their own sexuality and seldom are empowered to negotiate condom use in marital sex. As a result, these transitions are more likely to put forward serious challenges for reducing women's vulnerability to STI/HIV in India.

\section{Conclusion}

Our findings provide an initial view of the variation of transition in sexual partners among slum \& non-slum populations in the eight cities of India. A more exact assessment of the variation in sexual partner's transition among slum and non-slum populations requires data about the size, the prevalence of HIV infection across the social strata, and the types and frequency of sexual practices. Such an assessment would shape the future of HIV infection and STD transmission among slum and non-slum population.

\section{Acknowledgements}

We would like to acknowledge the mentoring support of Knowledge Network project, a grant to the Population Council from the Bill \& Melinda Gates Foundation through Avahan, the India AIDS Initiative. The views expressed herein are those of the authors and do not necessarily reflect the official policy or position of the Bill \& Melinda Gates Foundation and Avahan.

\section{References}

[1] National AIDS Control Organisation (2012) Technical Report India HIV Estimates-2012. National Institute of Medical Statistics, ICMR \& NACO, DAC, Ministry of Health \& Family Welfare, Government of India, New Delhi.

[2] Singh, S.K., Parasuraman, S. and Agrahari, K. (2010) A Profile of HIV Infected Persons in India. National Family Health Survey (NFHS-3), India, 2005-06. National Family Health Survey (NFHS-3), 2005-06. International Institute for Population Sciences, Mumbai, ICF Macro, Calverton.

[3] National AIDS Control Organisation (2014) HIV Sentinel Surveillance 2012-13: A Technical Brief. NACO, DAC, Ministry of Health \& Family Welfare, Government of India, New Delhi.

[4] Saggurti, N. and Malviya, A. (2009) HIV Transmission in Intimate Partner Relationships in India. Population Council, UNAIDS.

[5] Gupta, K., Arnold, F. and Lhungdim, H. (2009) Health and Living Conditions in Eight Indian Cities. National Family Health Survey (NFHS-3), India, 2005-06. International Institute for Population Sciences, Mumbai, ICF Macro, Calverton.

[6] Vinod, M., Medley, A., Hong, R., Gu, Y. and Robey, B. (2009) Levels and Spread of HIV Seroprevalence and Associated Factors: Evidence from National Household Surveys. DHS Comparative Reports No. 22, Macro International, Inc., Calverton.

[7] Sclar, E.D., Garau, P. and Carolini, G. (2005) The 21st Century Health Challenge of Slums and Cities. Lancet, 365, 901-903. http://dx.doi.org/10.1016/S0140-6736(05)71049-7

[8] Gupta, K., Arnold, F. and Lhungdim, H. (2009) Health and Living Conditions in Eight Indian Cities. National Family Health Survey (NFHS-3), 2005-06. International Institute for Population Sciences, Mumbai, ICF Macro, Calverton.

[9] International Institute for Population Sciences (IIPS) and Macro International (2007) National Family Health Survey (NFHS-3), 2005-06. Mumbai.

[10] International Institute for Population Sciences (IIPS) and Macro International (2007) National Family Health Survey (NFHS-3), 2005-06. Volume 2, Mumbai. 
Scientific Research Publishing (SCIRP) is one of the largest Open Access journal publishers. It is currently publishing more than 200 open access, online, peer-reviewed journals covering a wide range of academic disciplines. SCIRP serves the worldwide academic communities and contributes to the progress and application of science with its publication.

Other selected journals from SCIRP are listed as below. Submit your manuscript to us via either submit@scirp.org or Online Submission Portal.
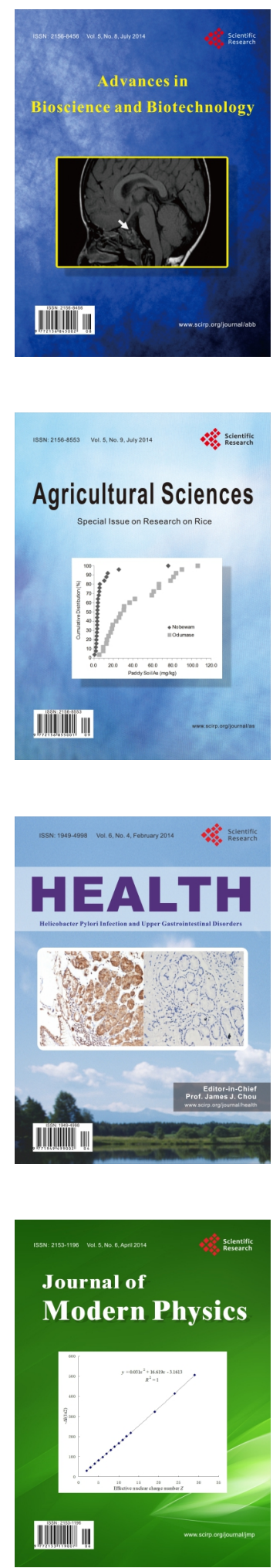
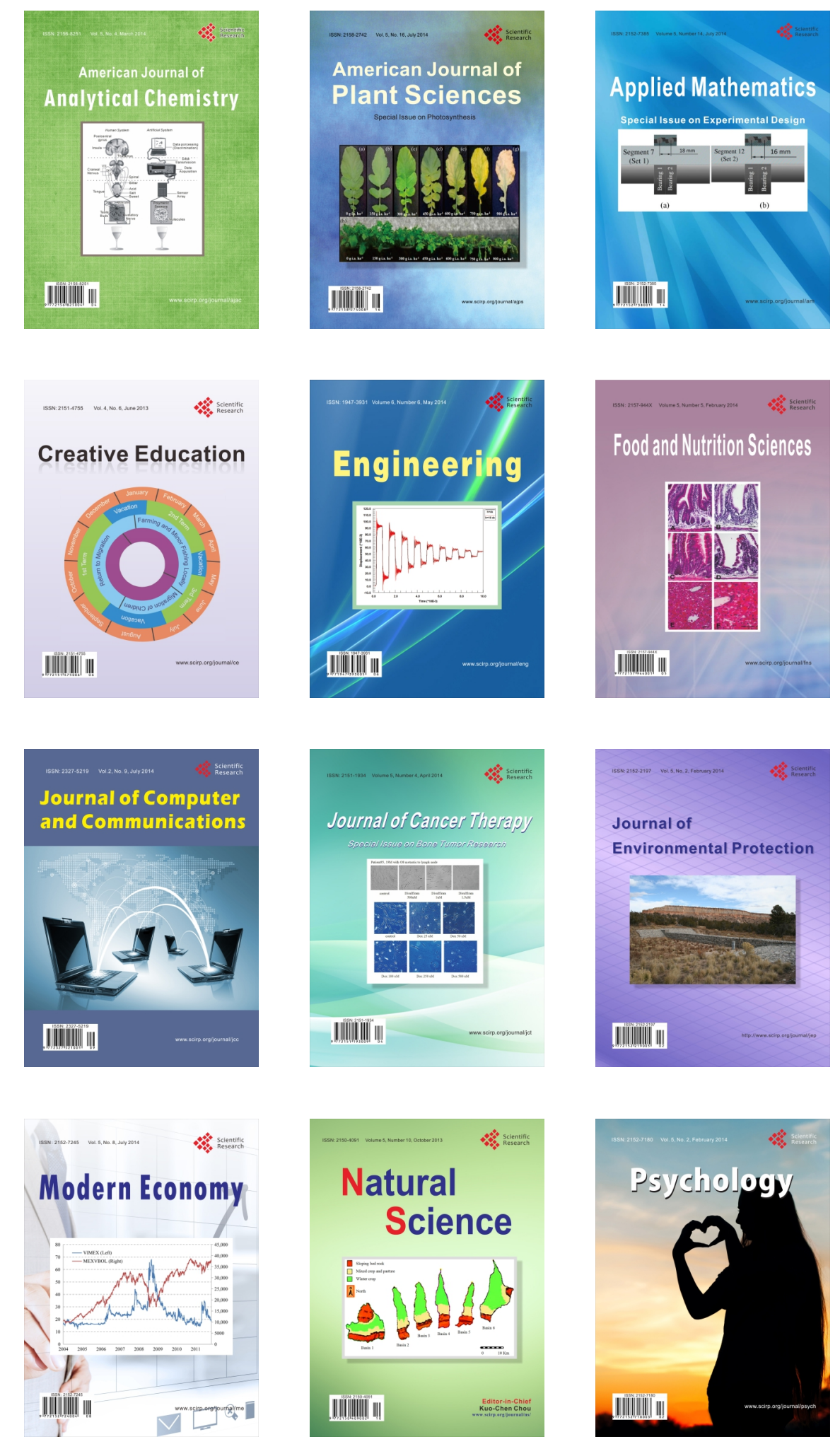